\title{
Antipyretic Effects of Citral and Possible Mechanisms of Action
}

\author{
Maycon T. Emílio-Silva, ${ }^{1}$ Clarissa M. D. Mota, ${ }^{1}$ Clélia A. Hiruma-Lima, ${ }^{2}$ \\ José Antunes-Rodrigues, ${ }^{1}$ Evelin C. Cárnio, ${ }^{3}$ and Luiz G. S. Branco ${ }^{4,5}$
}

\begin{abstract}
Citral is a mixture of the two monoterpenoid isomers (neral and geranial) widely used as a health-promoting food additive safe for human and animal (approved by the US Food and Drug Administration). In vitro studies have reported on the capability of citral to reduce inflammation. Here, we report antipyretic effects of citral in vivo using the most well-accepted model of sickness syndrome, i.e., systemic administration of lipopolysaccharide (LPS) to rats. Citral given by gavage caused no change in control euthermic rats (treated with saline) but blunted most of the assessed parameters related to the sickness syndrome [fever (hallmark of infection), plasma cytokines (IL-1 $\beta$, IL-6, and TNF- $\alpha$ ) release, and prostaglandin $\mathrm{E}_{2}\left(\mathrm{PGE}_{2}\right)$ synthesis (both peripherally and hypothalamic)]. Moreover, LPS caused a sharp increase in plasma corticosterone levels that was unaltered by citral. These data are consistent with the notion that citral has a corticosterone-independent potent antipyretic effect, acting on the peripheral febrigenic signaling (plasma levels of IL-1 $\beta$, IL- 6 , TNF- $\alpha$, and PGE 2 ), eventually downmodulating hypothalamic $\mathrm{PGE}_{2}$ production.
\end{abstract}

KEY WORDS: endotoxin; fever; LPS; IL-1 $\beta$; IL-6; TNF- $\alpha$; corticosterone; systemic inflammation; sickness syndrome.

\section{INTRODUCTION}

To help fight infectious diseases, the central nervous system respond with a set of autonomic, endocrine, and behavioral changes known as the sickness syndrome [24]. Among these changes, fever (a brain-regulated increase in deep body temperature $(\mathrm{Tb})$ that takes place during

\footnotetext{
${ }^{1}$ Medical School of Ribeirão Preto, University of São Paulo, 14049-900, Ribeirão Preto, São Paulo, Brazil

${ }^{2}$ Natural Products Laboratory, Department of Physiology, Bioscience Institute, Universidade Estadual Paulista 'Júlio de Mesquita Filho', Botucatu, São Paulo, 18618-970, Brazil

${ }^{3}$ Nursing School of Ribeirão Preto, University of São Paulo, Ribeirão Preto, São Paulo, 14040-902, Brazil

${ }^{4}$ Department of Morphology, Physiology and Basic Pathology, Dental School of Ribeirão Preto, University of São Paulo, Ribeirão Preto, SP 14040-904, Brazil

${ }^{5}$ To whom correspondence should be addressed at Department of Morphology, Physiology and Basic Pathology, Dental School of Ribeirão Preto, University of São Paulo, Ribeirão Preto, SP 14040-904, Brazil. Email: branco@forp.usp.br
}

inflammatory response) is essential to benefit the immune system and to improve survival [14].

A number of immune system cells have receptors for macromolecules usually found on invading organisms. For instance, toll-like receptor 4 (TLR4) binds endotoxin (lipopolysaccharide (LPS); a component of bacterial cell walls) and triggers an intracellular cascade causing the release of a number of cytokines [e.g., interleukin (IL)$1 \beta$, IL-6, and tumor necrosis factor (TNF)- $\alpha$ ] that eventually cause an increased production of prostaglandin $\mathrm{E}_{2}$ $\left(\mathrm{PGE}_{2}\right)$ in the anteroventral preoptic region of the hypothalamus (AVPO; the hierarchically most important region involved in thermoregulation). Moreover, both endogenous [4] and exogenous [24] modulators are known to potentiate or alleviate sickness syndrome.

Citral (3,7-dimethyl-2,6-octadienal) is a mixture of two isomers (cis-isomer neral and trans-isomer geranial) usually found in volatile oils of several plants, e.g., Zingiber officinale (ginger) [16] and Cymbopogon citratus (an herb commonly known as lemongrass). Moreover, lemongrass tea is usually 
taken as a spasmolytic, analgesic, anti-inflammatory, antipyretic, diuretic, and tranquilizer (cf. [22]). Recently, citral has been suggested as a potential therapeutic strategy for treatment of breast and other tumors [12]. However, no previous studies assessed the putative role of citral as an antipyretic molecule.

Thus, the aim of this work was to evaluate the effects of citral, administered via oral route, in the most well-accepted experimental model of systemic inflammation, i.e., peripheral injection of LPS to rats together with measurement of the levels of inflammatory mediators. Besides measuring $\mathrm{Tb}$, we assessed typical febrigenic mediators IL-1 $\beta$, IL-6, and $\mathrm{PGE}_{2}$ [18], as well as a cryogenic mediator TNF- $\alpha$ [15]. We also evaluated plasma corticosterone based on its anti-inflammatory actions known to attenuate fever during systemic inflammation [6]. Finally, besides these peripheral mediators, we also measured AVPO $\mathrm{PGE}_{2}$ production as a final indicator of the inflammatory status (cf. [4]).

\section{MATERIALS AND METHODS}

\section{Animals}

Male Wistar rats, weighting 260 to $320 \mathrm{~g}$, were housed (four animals per cage). After surgical procedures, the animals were caged individually for acclimation during 1 week. The room was kept on a 12:12 h light-dark cycle (lights on at 06:00 AM) with water and food ad libitum. Ambient temperature (Ta) was maintained at $25^{\circ} \mathrm{C}$ during experimental procedures. All protocols were approved by Local Ethical Committee for Animal Use (No. 2015.1.788.58.5).

\section{Surgeries}

Surgical procedures were performed under general anesthesia with ketamine-xylazine (100 and $10 \mathrm{mg} / \mathrm{kg}$, respectively; via intraperitoneal injection, ip). Rats were implanted with an abdominal SubCue miniature datalogger capsule (Calgary, Alberta, Canada) through midline laparotomy, for body core temperature $(\mathrm{Tb})$ measurements into the peritoneal cavity. After surgical procedures, each rat was treated prophylactically with antibiotic $(160,000 \mathrm{U} / \mathrm{kg}$ benzylpenicilin, $33.3 \mathrm{mg} / \mathrm{kg}$ streptomycin, and $33.3 \mathrm{mg} / \mathrm{kg}$ dihydrostreptomycin; $1 \mathrm{ml} / \mathrm{kg}$, intramuscular) and analgesic medication (Flunexine $2.5 \mathrm{mg} / \mathrm{kg}$ and $1 \mathrm{ml} / \mathrm{kg}$, subcutaneous). Experiments were performed 7 days after surgical procedures.

\subsection{Drugs}

Systemic inflammation was induced by Escherichia coli 0111:B4 LPS purchased from Sigma, St. Louis, MO, USA, and dissolved in pyrogen-free saline. Citral (also from Sigma, St. Louis, MO, USA) was dissolved in pyrogen-free saline diluted in $1 \%$ Tween 80 (Vetec, Rio de Janeiro, Brazil). Pyrogen-free saline and the solution with the final concentration of Tween 80 were administered to control rats.

\section{Experimental Design}

Protocol 1. This experimental protocol was designed to evaluate the effects of citral on euthermia or LPSinduced fever.

Rats were orally pretreated with vehicle $(10 \mathrm{~mL} / \mathrm{kg})$ or citral $(100 \mathrm{mg} / \mathrm{kg}) 30 \mathrm{~min}$ before the administration of LPS $(100 \mu \mathrm{g} / \mathrm{kg}$, i.p.) or saline ( $1 \mathrm{ml} / \mathrm{kg}$, i.p.) was administered (Fig. 1). Tb was measured for $5 \mathrm{~h}$, starting $1 \mathrm{~h}$ before the treatments. These doses of LPS [23] and citral [22] were chosen on the basis of previous studies and because, when preliminary doses were tested, the thermoregulatory responses to these doses were the most consistent and repeatable.

Protocol 2. The second experimental protocol was aimed at evaluating the plasma levels of cytokines (IL$1 \beta$, IL- 6 , and TNF- $\alpha$ ), corticosterone, and PGE2, 90 min after LPS administration.

Citral $(100 \mathrm{mg} / \mathrm{kg})$ or its vehicle was administered $30 \mathrm{~min}$ before LPS $(100 \mu \mathrm{g} / \mathrm{kg}$, i.p.) or saline $(1 \mathrm{ml} / \mathrm{kg}$, i.p.) was injected into rats. Ninety minutes after the administration of LPS or saline, the rats were decapitated and the blood was collected and processed as described below.

\section{AVPO Sampling}

Rats (previously treated with citral or its vehicle) were decapitated after 90 min after LPS or saline administration and their brains were quickly excised, promptly frozen by submersion in dry ice-cold isopentane, and stored at $-70{ }^{\circ} \mathrm{C}$. The AVPO of the hypothalamus was sampled in a cryostat by a punch needle (0.9-mm inner diameter) from a $500-\mu \mathrm{m}$-thick slice for the protocol 2 and $1500-\mu \mathrm{m}$-thick slice, based on the following landmarks: ventral, optic chiasm; dorsal, anterior commissure; and median, the $3 \mathrm{~V}$. Bilateral punches were taken just above the dorsal boundary of the optic chiasm and at the left and right lateral wall of the $3 \mathrm{~V}$. 


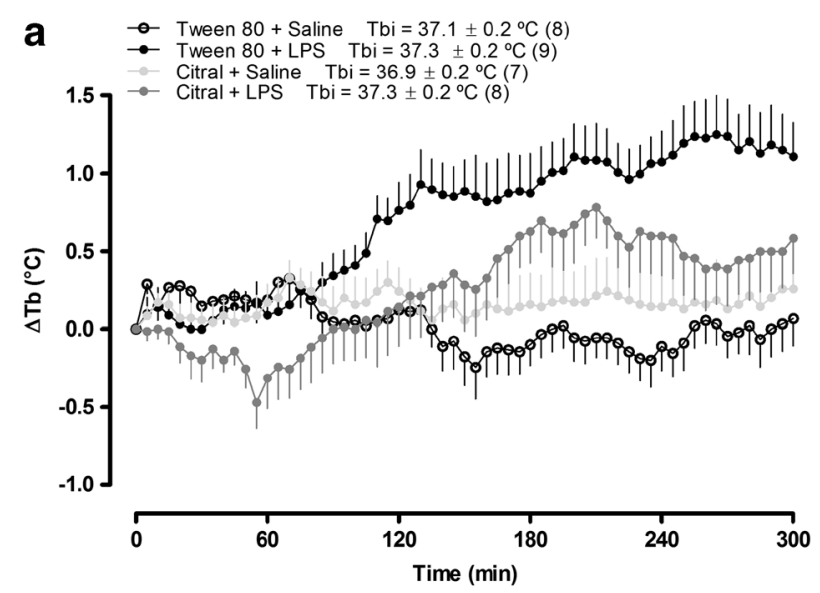

b

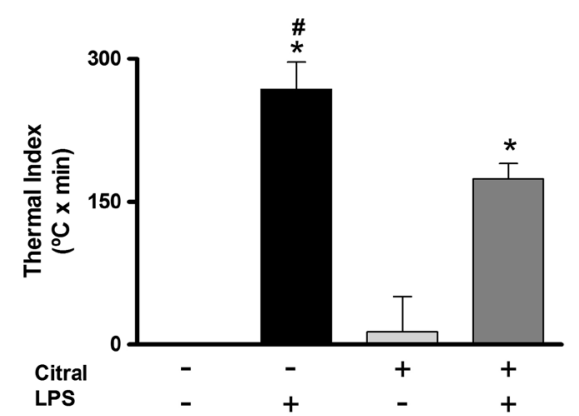

Fig. 1. Effect of citral on Tb. a Time courses showing the effects of citral $(100 \mathrm{mg} / \mathrm{kg}$ ) or vehicle (Tween 80 ) followed by administration of LPS ($100 \mu \mathrm{g} / \mathrm{kg}$, i.p.) or saline on Tb. b Thermal indexes (area under curve) calculated from each one of the four experimental groups. Number of animals in each group and Tbi values are shown in the legends. Data are presented as mean $\pm \mathrm{SEM}$.

\section{Measurements of Plasma Levels of Cytokines, $\mathrm{PGE}_{2}$, and Corticosterone}

Rats were decapitated 90 min after LPS treatment and the blood was collected in heparin-coated tubes. Afterwards, the tubes were centrifuged $(3.500 \mathrm{rpm}, 20 \mathrm{~min}$, $4{ }^{\circ} \mathrm{C}$ ) and plasma was stored at $-70{ }^{\circ} \mathrm{C}$. Plasma levels of IL-1 $\beta$, IL-6, and TNF- $\alpha$ were determined using specific enzyme-linked immunosorbent assay (ELISA) kits for each cytokine (R\&D Systems, Minneapolis, MN, USA) according to the manufacturer's instructions.

Plasma levels of $\mathrm{PGE}_{2}$ were determined using specific enzyme immunoassay (ELISA) kit for PGE2 (No. 514010, Cayman Chemical, MI, USA) according to the manufacturer's instructions. For analysis, the blood was collected in vacutainers containing EDTA and subsequent administration of indomethacin $(4 \mu \mathrm{l})$.

Plasma levels of corticosterone were assessed using a specific radioimmunoassay technique, as recently described [23]. It was measured using a specific radioimmunoassay after extraction with ethanol. Corticosterone antiserum was purchased from Sigma, and 1,2,6,7-3 Hcorticosterone from GE Healthcare Life Sciences (Milwaukee, WI, USA). The assay sensitivity and the intra- and inter-assay variability coefficients were $0.4 \mathrm{lg} / \mathrm{dl}, 5.1$ and $8.4 \%$, respectively.

\section{Measurement of $\mathrm{PGE}_{2}$ Concentration in the AVPO}

PGE2 levels were assessed using enzyme immunoassay (Prostaglandin E2 ELISA Kit - Monoclonal; Cayman Chemical, MI, USA) according to manufacturer's recommendations. AVPO were homogenized (VirTis, Gardiner, NY, USA) in EIA buffer concentrate $10 \times(100 \mu \mathrm{l})$ containing indomethacin $(4 \mu \mathrm{l})$. The resulting supernatants and pellets were used for $\mathrm{PGE}_{2}$ and protein determination, respectively, in summary form. Samples were reconstituted in assay buffer provided in the kit, incubated after $90 \mathrm{~min}$ in the dark, and optical density was measured at 405 to $420 \mathrm{~nm}$.

\section{Statistical Analysis}

Data are expressed as means \pm standard deviation (SD). Tb values $\left({ }^{\circ} \mathrm{C}\right)$ plotted at 5 -min intervals are shown as raw values (Fig. 1). Initial $\mathrm{Tb}$ (Tbi) represents the values of $\mathrm{Tb}$ measured at 5-min intervals averaged over the $60 \mathrm{~min}$ of the acclimatization period. Thermal index, expressed as ${ }^{\circ} \mathrm{C} \times \min$ (Fig. 1), were calculated from area under curve, from 0 to $300 \mathrm{~min}$. Plasma levels of IL-1 $\beta$, IL-6, TNF- $\alpha, \mathrm{PGE}_{2}$ (Fig. 2), and corticosterone (Fig. 3) are expressed as picograms per milliliter and micrograms per deciliter, respectively. AVPO $\mathrm{PGE}_{2}$ is expressed as picograms per milligram protein (Fig. 4). Statistical differences among groups were determined by two-way ANOVA followed by and Bonferroni post hoc test. The level of significance was set at $P<0.05$.

\section{RESULTS}

\section{Citral Exerts a Cryogenic Effect During LPS-Induced Fever}

In order to detect the effect of citral on thermoregulatory responses during euthermia and LPS-induced fever, $\mathrm{Tb}$ recordings were performed $60 \mathrm{~min}$ before and $5 \mathrm{~h}$ after administration of citral or Tween 80. Citral alone did not cause any significant change in $\mathrm{Tb}$ during euthermia (Fig. 1). As expected, LPS administration $(100 \mu \mathrm{g} / \mathrm{kg})$ induced a 

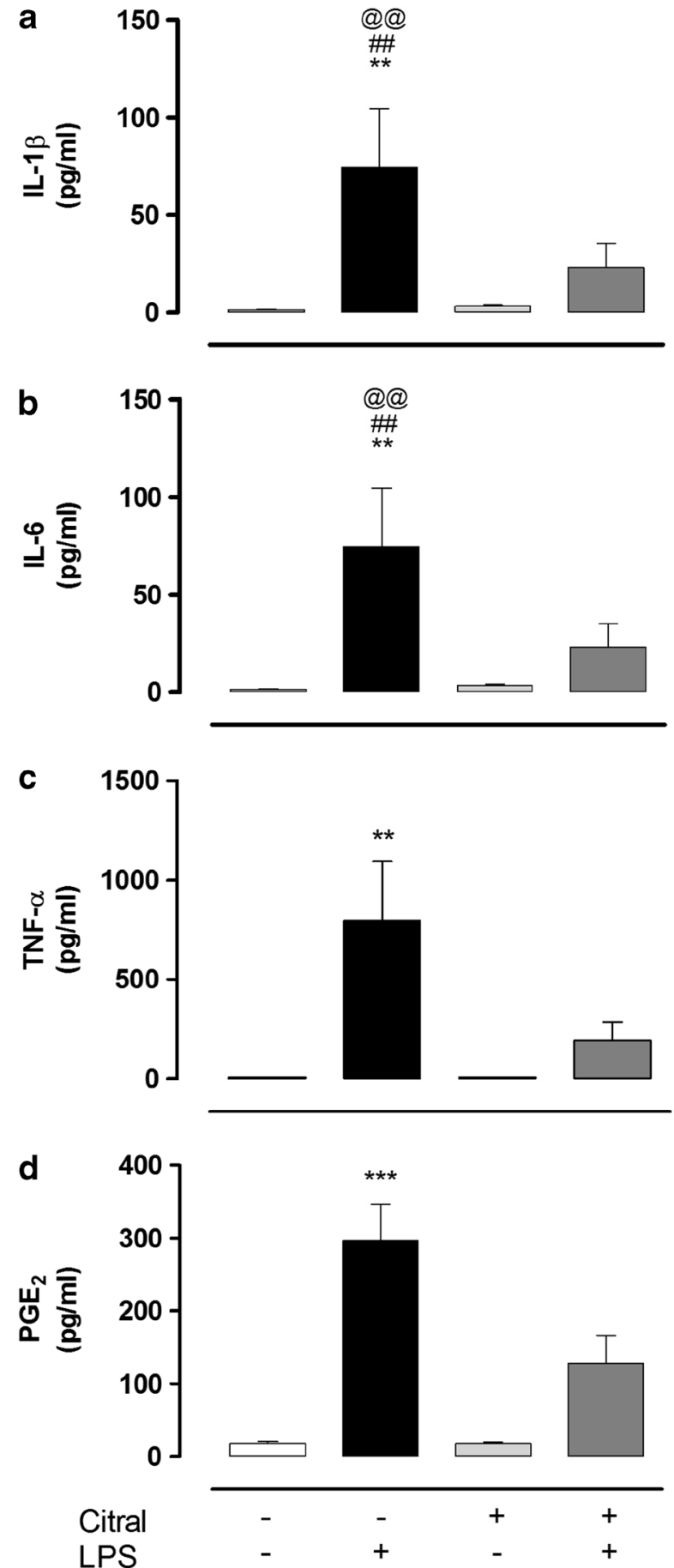

Fig. 2. Plasma cytokines concentration $(\mathrm{pg} / \mathrm{mL})$ after citral $(100 \mathrm{mg} / \mathrm{kg})$ combined or not with LPS $(100 \mu \mathrm{g} / \mathrm{kg}$, i.p.). Plasma levels of a interleukin$1 \beta$ (IL-1 $\beta$ ), b interleukin-6 (IL-6), c tumor necrosis factor $\alpha$ (TNF- $\alpha$ ), and d prostaglandin $\mathrm{E}_{2}\left(\mathrm{PGE}_{2}\right)$ were assessed. $* * p<0.01 ; * * * p<0.0001$ vs. Tween 80 -saline and Tween 80 -LPS; ${ }^{\# \#} p<0.01$ vs. Tween 80 -LPS and citral-saline; ${ }^{@} p<0.01$ vs. Tween 80 -LPS and citral-LPS. Data are presented as mean $\pm \operatorname{SEM}(n=6-8$ in each group).

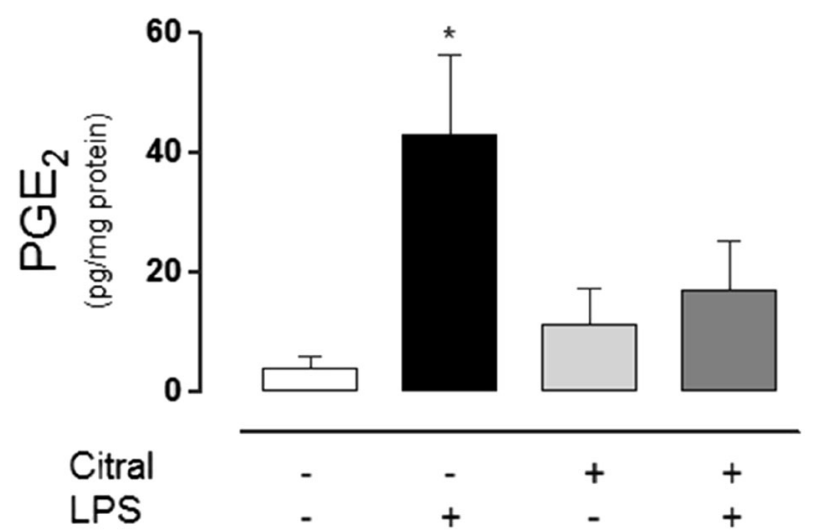

Fig. 3. AVPO prostaglandin $\mathrm{E}_{2}\left(\mathrm{PGE}_{2}\right)$ concentrations are shown. $* p<0$ .05 vs. Tween 80-saline and Tween 80-LPS. Data are presented as mean $\pm \operatorname{SEM}(n=7$ in each group).

typical polyphasic fever. This LPS-induced fever was attenuated when citral was given $(P>0.05$; Fig. 1).

Thermal indexes (area under curve) were calculated to clarify the changes in $\mathrm{Tb}$ observed in each one of the experimental groups. As shown in Fig. 1b, LPS given alone caused a significant $(P<0.05)$ increase in $\mathrm{Tb}$ (fever) of rats. This LPS-induced fever was attenuated when LPS treatment was combined with citral $(P>0.05)$.

\section{Citral Modulates Plasma Cytokines and $\mathrm{PGE}_{2}$ Concentration During Endotoxemia}

LPS markedly induced an increase in plasma levels of IL-1 $\beta$, IL-6, TNF- $\alpha$, and PGE2. Additionally, we observed that citral alone caused no significant change in plasma

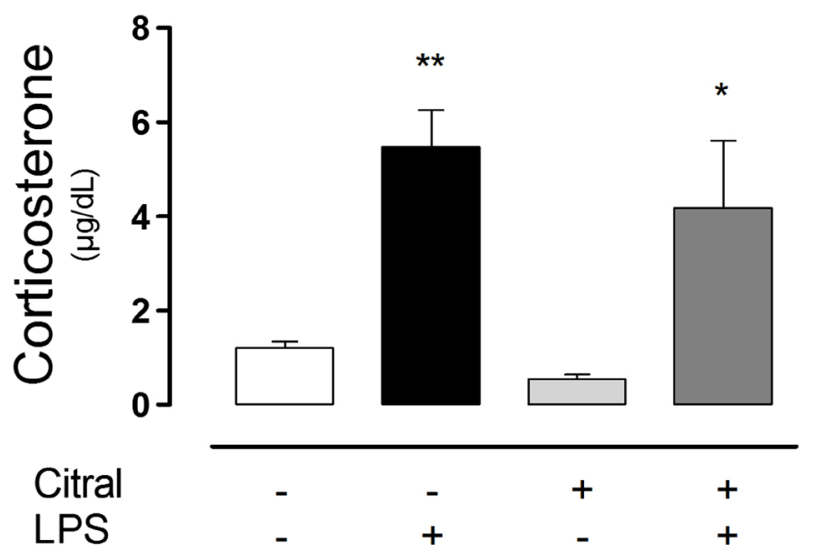

Fig. 4. Plasma corticosterone levels after systemic administration of LPS or saline, in rats pretreated with citral or vehicle. $* p<0.05 v s$. citral-saline and citral-LPS $* * p<0.01 v$ s. Tween 80 -saline and Tween 80 -LPS. Data are presented as mean $\pm \operatorname{SEM}(n=7$ in each group). 
cytokines of euthermic rats (Fig. 2) but prevented the LPSinduced rise in the plasma cytokines.

\section{Citral Modulates AVPO PGE 2 Production During Endotoxemia}

To further investigate the mechanism of action of citral, we measured AVPO $\mathrm{PGE}_{2}$ concentration. We observed an increased production during endotoxemia that was blunted when citral was co-administered (Fig. 3).

\section{Effect of Citral Combined or Not with LPS on Plasma Levels of Corticosterone}

Rats treated with citral did not present significant changes in corticosterone. The groups treated with LPS had significantly $(P<0.05)$ higher levels of corticosterone compared to the control groups (Fig. 4), and citral caused no significant change in this LPS-induced corticosterone increased plasma levels.

\section{DISCUSSION}

Acute inflammatory response plays a pivotal role following tissues injury. It may be beneficial and restore the tissues back to their healthy state, or it may be detrimental for instance during diseases/syndromes in which the inflammatory response yields negative or even lifethreatening scenarios, e.g., during trauma or sepsis when an up-regulated production of pro-inflammatory mediators can cause multiple organ failure or even death. Therefore, it is very important to understand how the acute inflammatory response is orchestrated and to test potential new pharmacological tools for the development of new therapeutic strategies. The present study provides several experimental evidences that citral plays a key antipyretic role in vivo during the most accepted model to study systemic inflammation. We observed that citral reduced the febrile response (Fig. 1), blunted the LPS-induced increase in plasma cytokines and plasma $\mathrm{PGE}_{2}$ levels (Fig. 2), and eventually caused a reduction of AVPO $\mathrm{PGE}_{2}$ production (Fig. 4). This antipyretic role of citral seems to be independent of plasma corticosterone (Fig. 3), since no significant differences were observed in this hormone levels when citral was administered.

In relation to studies addressing the effects of citral on nociceptive mechanisms, Stotz et al. [26] have documented that citral may inhibit transient receptor potential (TRP) channels and suggested that citral as a useful tool for allodynia and other types of pain. Moreover, citral has also reported to reduce nocifensive behavior and mechanical hyperalgesia [22].

Besides this anti-nociceptive effect, previous studies show that citral has also antitumor [12] and antibacterial activities [5, 10]. Moreover, Bachiega and Sforcin [1] have published a seminal article documenting that citral has antiinflammatory effects based on in vitro experiments [1]. A number of additional studies have assessed the effects of citral in vitro. For instance, citral has been reported to inhibit the enzyme nitric oxide synthase in LPSstimulated cells [13] and to decrease COX-2 LPS-induced expression [17]. However, the antipyretic effect of citral in vivo and its mechanisms of action were unclear. Therefore, the present study not only corroborates previous studies that assessed this issue using a different (in vitro) experimental approach but also elucidated some of citral's anti-inflammatory mechanism. This model is also apt to test putative thermoregulatory actions of a given compound, and the present study provides evident indication of a clear antipyretic role of citral.

Phagocytic cells (mainly macrophages) are the main source of inflammatory mediators (cytokines, for instance). After LPS administration, macrophages are activated and a number of intracellular events take place eventually causing transcriptional up-regulation of IL- $1 \beta$, IL-6, and TNF$\alpha$. This cytokines are among other systemic febrigenic signals that during systemic inflammation trigger a fairly elaborate response (namely acute phase response).

In the present study, plasma cytokines levels were measured $90 \mathrm{~min}$ after LPS administration based on the time course of $\mathrm{Tb}$ (Fig. 1) since this time precedes the febrile phases. It is worth mentioning that TNF- $\alpha$ levels have been reported to be highest at the same time, i.e., $90 \mathrm{~min}$ after LPS [3], but this is not the case for IL-1 $\beta$ [3] nor IL-6 [3, 19, 20] plasma levels, which reach peaks $2 \mathrm{~h}$ and $2-5 \mathrm{~h}$ after LPS administration, respectively. Thus, plasma cytokine levels measured in the present study reveal a specific inflammatory profile at given time $(90 \mathrm{~min}$ after LPS administration) and not a putative effect of citral at the peak of each one of the assessed cytokines.

Previous studies have reported the efficacy of systemic treatment with an IL-1 receptor antagonist (IL-1ra) in reducing LPS-induced fever in rats. For instance, Smith and Kluger [25] demonstrated that IL-1ra $(0.5 \mathrm{mg} / \mathrm{kg}$, ip) combined with LPS administration $(10 \mu \mathrm{g} / \mathrm{kg}$, ip) reduces LPS-induced fever $2-4 \mathrm{~h}$ after injection. Similarly, Luheshi et al. [20] showed that IL-1ra (16 mg/kg, ip) administrated 1 and $2 \mathrm{~h}$ after LPS $(100 \mu \mathrm{g} / \mathrm{kg}$, ip) delays the febrile response by $30 \mathrm{~min}$ and significantly reduces the peak of Tb during fever. More recently, Teeling et al. [27] reported 
that LPS $(100 \mu \mathrm{g} / \mathrm{kg}$, ip) causes increases in IL-1 $\beta$, IL-6, TNF- $\alpha$, and $\mathrm{PGE}_{2}$ levels in serum and brain of mice, and Nogueira et al. [23] demonstrated that LPS $(100 \mu \mathrm{g} / \mathrm{kg}$, ip) causes increases in plasma IL- $1 \beta$, IL- 6 , and TNF- $\alpha$ levels of sedentary rats. However, other studies have shown that IL-1 $\beta$ is not essential for the immune response to LPS in mice $[7,11]$. Interestingly, $\mathrm{Tb}$ of febrile humans following LPS administration is not significantly decreased with IL1 ra or TNF antibodies, as elegantly reported previously [8]. Therefore, important interspecies differences may exist. In agreement with this notion, the extracellular domain of the type I receptor has been reported to alleviate disease severity, in models of inflammatory and autoimmune diseases in rodents, whereas human type I receptor works as a carrier for IL- $1 \alpha$, and patients with rheumatoid arthritis worsens (cf. [8]). Besides the different species used, the divergences in the literature may occur due to the lineage of animals utilized and the different methods applied. However, there is a consensus that peripheral IL- $1 \beta$ is a result of immune activation [7-9]. Therefore, it is clear that the potential effect of citral on IL-1-induced fever continues as an important unanswered question to be addressed in the near future. Anyways, in the present study, we assessed cytokine plasma levels to unravel the mechanisms responsible for the citral's anti-inflammatory effect. Moreover, we also assessed $\mathrm{PGE}_{2}$ levels in the AVPO, because $\mathrm{PGE}_{2}$ is a proximal mediator of fever and AVPO is the hierarchically most important region involved in thermoregulation [2]. We observed that LPS caused an increase in plasma levels of cytokines and $\mathrm{PGE}_{2}$ (Fig. 2). Citral alone caused no changes on the cytokine plasma levels but prevented the LPS-induced increases in the cytokines and $\mathrm{PGE}_{2}$ plasma levels. Since AVPO $\mathrm{PGE}_{2}$ production reflects the peripheral febrigenic signaling, it is not surprising that we observed a reduced $\mathrm{PGE}_{2}$ AVPO content. However, we do not exclude a direct effect of citral reducing AVPO COX activity, as previously reported in in vitro experiments [17].

An interesting finding of this study is that citral antipyretic effect was not associated with an increased immune activation of the hypothalamic-pituitary-adrenal (HPA) axis (Fig. 4). The rationale to assess corticosterone levels is based on the fact that this hormone plasma levels may indicate the stress level. Interestingly, we observed a sharp LPS-induced increase in plasma corticosterone levels that was not affected by citral (Fig. 4), indicating that corticosterone may have affected the LPS-induced fever similarly in the two groups.

Taken together, our data are consistent with the notion that citral plays a major antipyretic role during LPSinduced systemic inflammation. This cryogenic role seems to be independent of plasma corticosterone levels. Conversely, its mechanisms of action involve a reduced release of plasma cytokines, combined with a decreased AVPO $\mathrm{PGE}_{2}$ production (Fig. 5). These findings may offer novel insights into strategies for controlling systemic inflammation.

\section{PERSPECTIVES AND SIGNIFICANCE}

To understand the mechanisms underlying the modulatory effect of citral during systemic inflammation, we adopted an experimental design that allows integrated analyses of the interaction among the nervous, endocrine, and immune systems.

Human's modern life style leads to loss of muscle mass and increase of intra-abdominal fat deposition. This adiposity increases macrophage infiltration and triggers the activation of inflammatory cascade reactions causing systemic inflammation and thus favoring insulin resistance, atherosclerosis, and tumor growth. Therefore, individuals

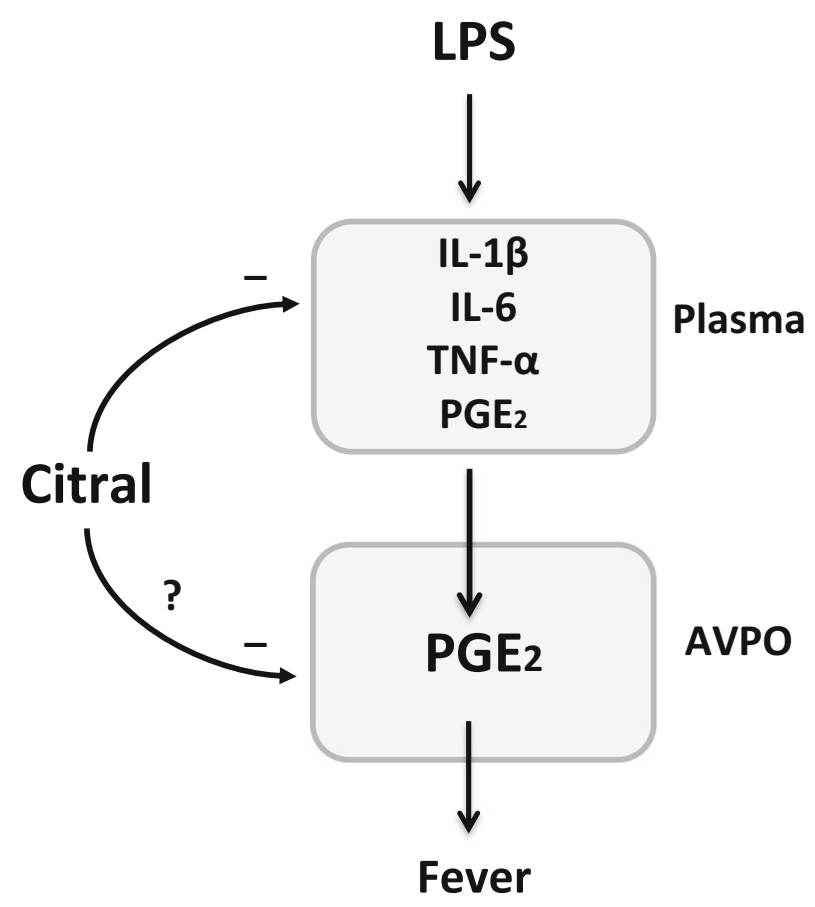

Fig. 5.. Possible mechanisms involved in citral-induced attenuation of systemic inflammation. LPS induces increase in cytokine plasma levels. This increased febrigenic signaling stimulates $\mathrm{AVPO} \mathrm{PGE}_{2}$ production and eventually fever. Citral reduces LPS-induced increases of plasma cytokines and consequently also reducing AVPO $\mathrm{PGE}_{2}$ production. Additionally, we speculate that citral may also reduce $\mathrm{PGE}_{2}$ production directly (marked with “?”). 
tend to develop type 2 diabetes mellitus, cardiovascular diseases, and cancer. Conversely, there is a number of evidence to suggest that many foods/nutrients can modulate inflammation both acutely and chronically [21]. The present study adds citral as a potential substance suitable to prevent or reduce systemic inflammation.

\section{COMPLIANCE WITH ETHICAL STANDARDS}

Funding Sources. This study was funded by Grant No. 2016/17681-9 São Paulo Research Foundation (FAPESP) and National Council for Scientific and Technological Development (CNPq), Brazil.

Conflict of Interest. The authors declare that they have no conflict of interest.

\section{REFERENCES}

1. Bachiega, T.F., and J.M. Sforcin. 2011. Lemongrass and citral effect on cytokines production by murine macrophages. Journal of Ethnopharmacology 137: 909-913.

2. Blatteis, C.M. 2006. Endotoxic fever: New concepts of its regulation suggest new approaches to its management. Pharmacology \& Therapeutics 111: 194-223.

3. Blatteis, C.M., and E. Sehic. 1998. Cytokines and fever. Annals of the New York Academy of Sciences 840: 608-618.

4. Branco, L.G., R.N. Soriano, and A.A. Steiner. 2014. Gaseous mediators in temperature regulation. Comprehensive Physiology 4: 1301-1338.

5. Chaouki, W., D.Y. Leger, B. Liagre, J.L. Beneytout, and M. Hmamouchi. 2009. Citral inhibits cell proliferation and induces apoptosis and cell cycle arrest in MCF-7 cells. Fundamental \& Clinical Pharmacology 23: 549-556.

6. Coelho, M.M., G.E. Souza, and I.R. Pela. 1992. Endotoxin-induced fever is modulated by endogenous glucocorticoids in rats. American Journal Physiology 263: R423-R427.

7. Dinarello, C.A. 2004. Infection, fever, and exogenous and endogenous pyrogens: Some concepts have changed. Journal of Endotoxin Research 10: 201-222.

8. Dinarello, C.A. 2009. Immunological and inflammatory functions of the interleukin-1 family. Annual Review of Immunology 27: 519-550.

9. Dinarello, C.A., H.A. Bernheim, J.G. Cannon, G. Lopreste, S.J.C. Warner, A.C. Webb, and P.E. Auron. 1985. Purified, ${ }^{35} \mathrm{MET}$, ${ }_{3}$-LEUlabelled human monocyte interleukin-1 (IL-1) with endogenous pyrogen activity. British Journal of Rheumatology 24: 59-64.

10. Dudai, N., Y. Weinstein, M. Krup, T. Rabinski, and R. Ofir. 2005. Citral is a new inducer of caspase-3 in tumor cell lines. Planta Medica 71: 484-488.

11. Fantuzzi, G., H. Zheng, R. Faggioni, F. Benigni, P. Ghezzi, J.D. Sipe, A.R. Shaw, and C.A. Dinarello. 1996. Effect of endotoxin in IL-1 beta-deficient mice. The Journal of Immunology 157: 291-296.
12. Kapur, A., M. Felder, L. Fass, J. Kaur, A. Czarnecki, K. Rathi, S. Zeng, K.K. Osowski, C. Howell, M.P. Xiong, R.J. Whelan, and M.S. Patankar. 2016. Modulation of oxidative stress and subsequent induction of apoptosis and endoplasmic reticulum stress allows citral to decrease cancer cell proliferation. Scientific Reports 6: 27530.

13. Katsukawa, M., R. Nakata, Y. Takizawa, K. Hori, S. Takashi, and H. Inoue. 2010. Citral, a component of lemongrass oil, activates PPAR $\alpha$ and $\gamma$ and suppresses COX-2 expression. Biochimica et Biophysica Acta 1801: 1214-1220.

14. Kluger, M.J., D.H. Ringler, and M.R. Anver. 1975. Fever and survival. Science 188 (4184): 166-168.

15. Kozak, W., C.A. Conn, J.J. Klir, G.H. Wong, and M.J. Kluger. 1995. TNF soluble receptor and antiserum against TNF enhance lipopolysaccharide fever in mice. American Journal Physiology Regul Integr Comp Physiol 269: R23-R29.

16. Lai, Y.S., W.C. Lee, Y.E. Lin, C.T. Ho, K.H. Lu, S. Panyod, Y.L. Chu, and L.Y. Sheen. 2016. Ginger essential oil ameliorates hepatic injury and lipid accumulation in high fat diet-induced nonalcoholic fatty liver disease. Journal of Agricultural and Food Chemistry 64: 2062-2071.

17. Lee, H.J., H.S. Jeong, D.J. Kim, Y.H. Noh, D.Y. Yuk, and J.T. Hong. 2008. Inhibitory effect of citral on NO production by suppression of iNOS expression and NF-kappa B activation in RAW264.7 cells. Archives of Pharmacology Research 31: 342-349.

18. Leon, L.R. 2002. Invited review: Cytokine regulation of fever: Studies using gene knockout mice. Journal of Applied Physiology 92: 2648-2655.

19. Libert, C., P. Brouckaert, A. Shaw, and W. Fiers. 1990. Induction of interleukin 6 by human and murine recombinant interleukin 1 in mice. European Journal of Immunology 20: 691-614.

20. Luheshi, G., A.J. Miller, S. Brouwer, M.J. Dascombe, N.J. Rothwell, and S.J. Hopkins. 1996. Interleukin-1 receptor antagonist inhibits endotoxin fever and systemic interleukin-6 induction in the rat. American Journal of Physiology 270: E91-E95.

21. Minihane, A.M., S. Vinoy, W.R. Russell, A. Baka, H.M. Roche, K.M. Tuohy, J.L. Teeling, E.E. Blaak, M. Fenech, D. Vauzour, H.J. McArdle, B.H. Kremer, L. Sterkman, K. Vafeiadou, M.M. Benedetti, C.M. Williams, and P.C. Calder. 2015. Low-grade inflammation, diet composition and health: Current research evidence and its translation. British Journal of Nutrition 114 (7): 999-1012.

22. Nishijima, C.M., E.G. Ganev, L. Mazzardo-Martins, D.F. Martins, L.R.M. Rocha, A.R.S. Santo, and C.A. Hiruma-Lima. 2014. Citral: A monoterpene with prophylacticand therapeutic anti-nociceptive effects in experimental models of acute and chronic pain. European Journal of Pharmacology 736: 16-25.

23. Nogueira, J.E., R.N. Soriano, R.A.R. Fernandez, H.D.C. Francescato, R.S. Saia, and T.M. Coimbra. 2017. Effect of physical exercise on the febrigenic signaling is modulated by preoptic hydrogen sulfide production. PloS One 12 (1): e 0170468.

24. Saper, C.B., A.A. Romanovsky, and T.E. Scammell. 2012. Neural circuitry engaged by prostaglandins during the sickness syndrome. Nature Neurosciense 15: 1088-1095.

25. Smith, B.K., and M.J. Kluger. 1992. Human IL-1 receptor antagonist partially suppresses LPS fever but not plasma levels of IL-6 in Fischer rats. American Journal of Physiology 263: R653-R655.

26. Stotz, S.C., J. Vriens, D. Martyn, J. Clardy, and D.E. Clapham. 2008. Citral sensing by transient receptor potential channels in dorsal root ganglion neurons. PloS One 3 (5): e2082.

27. Teeling, J.L., C. Cunningham, T.A. Newman, and V.H. Perry. 2010. The effect of non-steroidal anti-inflammatory agents on behavioural changes and cytokine production following systemic inflammation: Implications for a role of COX-1. Brain, Behavior and Immunity 24: 409-419. 